\title{
Effect of dietary supplementation of Ashwagandha (Withania somnifera) and Selenium on growth performance and carcass quality of broilers
}

MANOJ KUMAR SINGH, V.P. SINGH, D.S. SAHU AND JINU MANOJ

Author for Corresponding -

MANOJ KUMAR SINGH

Department of Livestock Production Management, College of Veterinary and Animal Sciences, Sardar Vallabhbhai Patel University of Agriculture and Technology, MEERUT (U.P.) INDIA

Email : drmanoj611@gmail. com

See end of the article for Coopted authors'
ABSTRACT...... Poultry meat is an excellent source of high quality protein, vitamins and minerals and is not subjected to cultural and religious restrictions. Incorporation of herbal plants and vitamins in the feed of broilers are more acceptable to health conscious consumers. Selenium, an essential micronutrient, has various biological roles in poultry and it is needed for normal growth and maintenance in them. The current study was designed to study the combined effect of Ashwagandha and Selenium on growth performance and carcass traits of broilers. Day old chicks $(n=60)$ were selected and divided in to six groups, with 3 replicates of each group, 20 chicks in each replicate. Ashwagandha and Selenium were supplemented in broiler chicken feed at different levels for different group. The growth performance of broilers were assessed in terms of weekly body weight gain and feed conversion ratio. The carcass quality was analyzed based on dressing percentage, drumstick weight, giblet weight, cooking yield and $\mathrm{pH}$ of fresh chicken meat. The data obtained in the present study were analyzed statistically by using Complete Randomized Design one way Anova procedure of SPSS version 20. Average body weight gain of broilers groups treated simultaneously with both the Ashwagandha and Selenium showed significant $(\mathrm{P}<0.05)$ difference when compared to other groups. The highest body weight gain was found during the third week of the trial and for the treatment group $\mathrm{T}_{5}$. The carcass traits were also found better in Ashwagandha and Selenium treated groups due to the synergistic effect of these dietary inclusions. The current study recommends an inclusion of Ashwagandha and Selenium in the broiler diet at level of 2.5 per cent and $0.20 \mathrm{mg} / \mathrm{kg}$, respectively for the improvement of growth performance and carcass traits in broiler chicken.

KEY WORDS...... Ashwagandha, Broiler, Carcass, Growth, Selenium

HOW TO CITE THIS ARTICLE - Singh, Manoj Kumar, Singh, V.P., Sahu, D.S. and Manoj, Jinu (2017). Effect of dietary supplementation of Ashwagandha (Withania somnifera) and Selenium on growth performance and carcass quality of broilers. Asian J. Animal Sci., 12(2): 129-133. DOI : 10.15740/HAS/ TAJAS/12.2/129-133.

ARTICLE CHRONICLE - Received : 17.07.2017; Revised : 08.11.2017; Accepted : 22.11.2017 